\title{
Sec61alpha synthesis is enhanced during translocation of nascent chains of collagen type IV in F9 teratocarcinoma cells after retinoic acid treatment
}

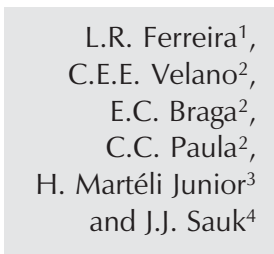

Correspondence

L.R. Ferreira

Rua Manoel Pedro Rodrigues, 145

37130-000 Alfenas, MG

Brasil

E-mail: resende@pucpcaldas.br

.....................

Received June 5, 2001

Accepted October 4, 2002

.....................

\author{
${ }^{1}$ Grupo de Pesquisa em Biomedicina, Departamento de Ciências Morfológicas, \\ Pontifícia Universidade Católica de Minas Gerais, Poços de Caldas, MG, Brasil \\ ${ }^{2}$ Departamento de Clínica Médica, Faculdade de Medicina, Universidade de Alfenas, \\ Alfenas, MG, Brasil \\ ${ }^{3}$ Departamento de Periodontia, Faculdade de Odontologia, Universidade de Alfenas, \\ Varginha, MG, Brasil and Universidade de Montes Claros, Montes Claros, MG, Brasil \\ ${ }^{4}$ Department of Oral Pathology, Dental School, University of Maryland, Baltimore, \\ MD, USA
}

\begin{abstract}
Nascent procollagen peptides and other secretory proteins are transported across the endoplasmic reticulum (ER) membrane through a protein-conducting channel called translocon. Sec61 $\alpha$, a multispanning membrane translocon protein, has been implicated as being essential for translocation of polypeptide chains into the cisterns of the ER. Sec61 $\alpha$ forms a protein complex with collagen and Hsp47, an ERresident heat shock protein that binds specifically to collagen. However, it is not known whether Sec61 $\alpha$ is ubiquitously produced in collagen-producing F9 teratocarcinoma cells or under heat shock treatment. Furthermore, the production and utilization of Sec61 $\alpha$ may depend on the stage of cell differentiation. Cultured F9 teratocarcinoma cells are capable of differentiation in response to low concentrations of retinoic acid. This differentiation results in loss of tumorigenicity. Mouse F9 cells were grown in culture medium at $37^{\circ} \mathrm{C}$ and $43^{\circ} \mathrm{C}$ (heat shock treatment) treated or not with retinoic acid, and labeled in certain instances with ${ }^{35} \mathrm{~S}$-methionine. Membrane-bound polysomes of procollagen IV were then isolated. Immunoprecipitation and Western blot analysis were performed using polyclonal antibodies against collagen IV, Hsp47 and Sec61 $\alpha$. Under retinoic acid-untreated conditions, F9 cells produced undetectable amounts of Sec61 $\alpha$. Sec61 $\alpha$, Hsp47 and type IV collagen levels were increased after retinoic acid treatment. Heat shock treatment did not alter Sec61 $\alpha$ levels, suggesting that Sec61 $\alpha$ production is probably not affected by heat shock. These data indicate that the enhanced production of Sec61 $\alpha$ in retinoic acid-induced F9 teratocarcinoma cells parallels the increased synthesis of Hsp47 and collagen type IV.
\end{abstract}

Key words - Sec61a

- Collagen type IV

- Retinoic acid

- F9 cells

- Differentiation 


\section{Introduction}

Secretory proteins are transported across the endoplasmic reticulum (ER) membrane through a protein-conducting channel $(1,2)$. This protein-conducting channel consists of ER-associated proteins forming a translocon, which includes the translocon-associated protein, the translocating chain-associating membrane protein (TRAM) and the Sec61p complex $(1,2)$. TRAM and Sec61p are tightly associated with membrane-bound ribosomes, suggesting that polypeptide nascent chains pass directly from the ribosome into a protein-conducting channel $(3,4)$.

The Sec61p complex is composed of three subunits: $\alpha, \beta, \gamma(5)$. Sec $61 \alpha$, a multispanning membrane protein and the largest component of the Sec61p complex, is essential for translocation of polypeptide chains through this channel into the cisterns of the ER (5). The Sec61p complex is homologous to SecYp present in bacteria (6).

The translocation process requiring the Sec61p complex in mammalian cells is associated with a specialized co-translational pathway in which the nascent polypeptide is continuously bound to polysome-bound ribosomes as it translocates through the ER membrane (7). Photocrosslinking experiments and studies involving chemical crosslinking reagents such as dithio-bis-succinimidyl propionate (DSP) or disuccinimidylsuberate have shown that $\operatorname{Sec} 61 \alpha$ is closely associated with nascent polypeptides undergoing translocation across mammalian rough ER including collagen and Hsp47 $(3,8)$.

Hsp47 is a $47-\mathrm{kDa}$ collagen-binding glycoprotein localized in the ER of collagenproducing cells (9). Hsp47 binds primarily to collagens, procollagen in particular, but may also associate with fetuin (10). Hsp47 is constitutively expressed, as well as affected by environmental stresses such as heat shock $(11,12)$. Following heat shock, Hsp47 protein levels rapidly increase through an acti- vation of heat shock transcription factors (13). Immunoprecipitation studies have revealed that Hsp47 is closely associated with the translation-translocation machinery during the production of procollagen I, suggesting that Hsp47 might function as a molecular chaperone for nascent chains of collagen $(14,15)$. The levels of Hsp47 have been shown to vary with collagen concentration following retinoic acid-induced differentiation of mouse teratocarcinoma cells (16), in pathological conditions such as hepatic, renal and pulmonary fibrosis (17-20), and in cultured fibroblasts grown from patients with hereditary gingival fibromatosis (21).

In the present study, we tested the proposition that the translocation of secretory proteins through the ER membrane is the result of the enhanced production and utilization of Sec61 $\alpha$ and may depend on the stage of cell differentiation. However, it is not known whether Sec61 $\alpha$ is produced ubiquitously in all collagen-producing cells or under heat shock treatment. Stem cells from many cultured teratocarcinoma cell lines such as mouse F9 and P19 cells are capable of differentiation in response to low concentrations of retinoic acid, a derivative of vitamin A (22). This differentiation of tumorigenic stem cells results in the loss of tumorigenicity (23). Therefore, teratocarcinoma cell lines provide a model to examine the association between the process of cell differentiation and the production of Sec61 $\alpha$.

We determined the synthesis of Sec61 $\alpha$ and Hsp47 during translocation of collagen nascent chains in $\mathrm{F} 9$ cells following retinoic acid and heat shock treatment.

\section{Material and Methods}

\section{Cell culture and metabolic labeling}

F9 teratocarcinoma cells, obtained from the American Type Tissue Culture Collection (Rockville, MD, USA), were grown to confluence in $75-\mathrm{cm}^{2}$ plastic flasks using 
Dulbecco's modified Eagle's medium (DMEM), 10\% fetal bovine serum, $1.16 \mathrm{~g} / 1$ glutamine, and $100 \mathrm{mg} / \mathrm{ml}$ streptomycin at $37^{\circ} \mathrm{C}$ in $5 \% \mathrm{CO}_{2}$. For the cell growth experiments, F9 stem cells $\left(1 \times 10^{5}\right.$ cells $)$ were plated onto gelatinized tissue culture plates containing $10 \mathrm{ml}$ of medium. Mouse F9 cells were induced to differentiate into parietal endoderm cells after treatment with all-trans retinoic acid $(10 \mu \mathrm{M})$ for 4 days. When it was necessary to label proteins, the medium was removed and replaced with fresh methionine-free DMEM containing ${ }^{35} \mathrm{~S}$-methionine $(100 \mu \mathrm{Ci} / \mathrm{ml}$; New England Nuclear, Boston, MA, USA) for 20 min under normal conditions $\left(37^{\circ} \mathrm{C}\right)$ or for $90 \mathrm{~min}$ at $43^{\circ} \mathrm{C}$ for heat shock. ${ }^{35} \mathrm{~S}$-methionine was used to label nascent chains of collagen and Hsp47.

\section{Immunoprecipitation and analysis by gel electrophoresis}

The ${ }^{35} \mathrm{~S}$-methionine-labeled F9 cells were collected and incubated in lysis buffer (50 $\mathrm{mM}$ Tris- $\mathrm{HCl}, \mathrm{pH} 8.0,40 \mathrm{mM} \mathrm{NaCl}, 5 \mathrm{mM}$ EDTA) at $4^{\circ} \mathrm{C}$ for $30 \mathrm{~min}$. Rabbit antibodies against mouse type IV collagen, Hsp47, and Sec61 $\alpha$ (diluted 1:2000) were added to the samples. The samples $(100 \mu \mathrm{l})$ were incubated for $2 \mathrm{~h}$ at $4^{\circ} \mathrm{C}$, then precipitated with 30 $\mu l$ of protein A-Sepharose. The precipitated immune complexes were washed three times with $1 \mathrm{ml}$ of lysis buffer, and once with $1 \mathrm{ml}$ of $10 \mathrm{mM}$ Tris-HCl, $\mathrm{pH}$ 6.8. The samples were suspended in Laemmli's sodium dodecyl sulfate-polyacrylamide gel electrophoresis (SDS-PAGE) buffer (1.25 M Tris- $\mathrm{HCl}$, $\mathrm{pH} 6.8,10 \%$ SDS in distilled water, $30 \%$ bromophenol blue in glycerol and $0.5 \%$ mercaptoethanol), and boiled for $5 \mathrm{~min}$. Twentyfive microliters of the supernatant was loaded onto $4-20 \%$ polyacrylamide gels by the method of Laemmli (24). The gels were fixed, dried and autoradiographed using the method of Bonner and Laskey (25). In some instances, treatment with a cleavable bifunctional membrane permeable cross-linking reagent, DSP, was performed prior to immunoprecipitation (16). After labeling, cells were harvested and rinsed with phosphatebuffered solution (PBS). Cells were then treated with $0.1 \%$ collagenase to remove the extracellular collagen. After rinsing in PBS, cells were combined with $2 \mathrm{ml}$ DSP $(0.1 \%$ in DMSO) and placed on ice for $30 \mathrm{~min}$. After $30 \mathrm{~min}$ the cells were rinsed with $2 \mathrm{mM}$ glycine in PBS and lysed in lysis buffer with $50 \mu \mathrm{g} / \mathrm{ml}$ gelatin on ice for $15 \mathrm{~min}$. The supernatants were then divided into equal aliquots and immunoprecipitation was performed as described above.

\section{Isolation of membrane-bound polysomes (microsomes) and collagenase digestion}

Microsomes from F9 cells were isolated by the method of Vedeler et al. (26). After microsomes were collected, immunoprecipitation was performed as previously described. In some cases, collagenase digestion was performed before adding Laemmli's buffer. Microsome extracts were incubated with 2.7 $\mathrm{U}$ of bacterial collagenase in $50 \mu \mathrm{l}$ collagenase buffer $(10 \mathrm{mM}$ Tris, $\mathrm{pH} 7.5,40 \mathrm{mM}$ $\mathrm{NaCl}, 5 \mathrm{mM} \mathrm{CaCl}_{2}, 30 \mathrm{mM} \mathrm{KCl}, 10 \mathrm{mM}$ PMSF, $50 \mu \mathrm{M}$ N-ethylmaleimide, $2.5 \mathrm{mM}$ benzamidine) and incubated for $1 \mathrm{~h}$ at $37^{\circ} \mathrm{C}$. Laemmli's buffer was then added to the samples, the samples were boiled for $5 \mathrm{~min}$ and the immunoprecipitated microsomes bound to protein A-Sepharose were released and collected. SDS-PAGE and autoradiography were performed as previously described.

\section{Western blotting by enhanced chemiluminescence}

F9 microsomes were isolated and analyzed by SDS-PAGE as described above. The microsomes were then electrotransferred to a nitrocellulose filter (27). The filter was blocked for $1 \mathrm{~h}$ with $10 \%$ dried milk in PBS and rinsed three times with PBS. Anti- 
bodies against TRAM or Sec61 $\alpha$ (Biopolymer Laboratories, Baltimore, MD, USA) diluted $1: 2,000$ in $5 \%$ dried milk/1\% BSA in PBS were added, and the filter was incubated overnight at room temperature. The filter was washed four times with PBS in $0.2 \%$ Tween 20 and incubated for $2 \mathrm{~h}$ at room temperature with a secondary goat anti-mouse IgG antibody (Amersham Inc., Arlington Heights, IL, USA) diluted 1:2000 in $1 \%$ BSA in PBS, in order to reduce nonspecific binding according to Towbin et al. (27). The filter was then washed in PBS and incubated with enhanced chemiluminescence reagents for $1 \mathrm{~min}$ according to the manufacturer protocol (Amersham). An X-ray film was exposed to the filter for less than a minute.

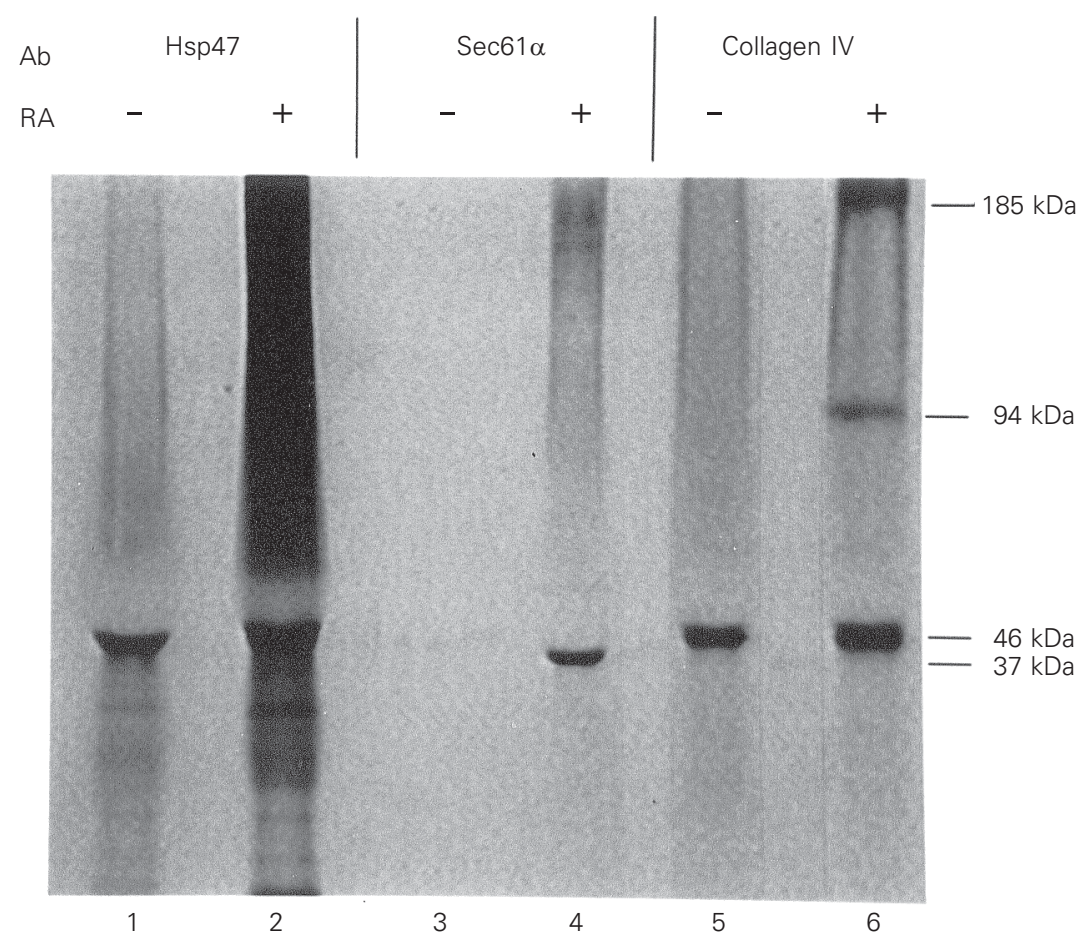

Figure 1. Immunoprecipitation of membrane-bound polysomes (microsomes) with antiHsp47, anti-Sec61 $\alpha$, and anti-collagen IV antibodies after retinoic acid treatment of F9 cells. Cells treated (lanes 2, 4 and 6) or not (lanes 1, 3 and 5) with retinoic acid for 4 days were labeled for $1 \mathrm{~h}$ with ${ }^{35} \mathrm{~S}$-methionine. Microsomes were immonoprecipitated with anti-Hsp47 (lanes 1 and 2), anti-Sec61 $\alpha$ (lanes 3 and 4), and anti-collagen IV (lanes 5 and 6) antibodies. Ab: antibody; RA: all-trans retinoic acid. Molecular masses of standard proteins are given on the right side of the figure.

\section{Results}

It is not known whether Sec61 $\alpha$ is ubiquitously expressed and produced in collagenproducing cells. Furthermore, it is also not clear whether this binding occurs through the enhanced production and utilization of Sec61 $\alpha$ and whether it might be dependent on the stage of cell differentiation. In order to answer these questions, we treated F9 cells with all-trans retinoic acid for 4 days, followed by labeling with ${ }^{35} \mathrm{~S}$-methionine. Membrane-bound polysomes (microsomes) were extracted from the cells according to the method of Vedeler et al. (26). The effect of all-trans retinoic acid on the synthesis of Hsp47 (47 kDa), collagen IV (170- to 185$\mathrm{kDa}$ bands which correspond to $\alpha 2$ and $\alpha 1$ chains, respectively) and Sec61 $\alpha$ is shown in Figure 1. Anti-Sec61 $\alpha$ antibodies immunoprecipitated a protein of approximately $37-38 \mathrm{kDa}$ in samples treated with retinoic acid (Figure 1, lane 4), while no bands were detected in control samples (Figure 1, lane 3). Treatment of F9 cells with retinoic acid resulted in increased collagen and Hsp47 synthesis (Figure 1, lane 6).

To assess whether $\operatorname{Sec} 61 \alpha$ is closely associated with Hsp47 and nascent collagen chains, a cross-linking agent, DSP, was added to the samples prior to immunoprecipitation (Figure 2). Anti-Hsp47 antibodies immunoprecipitated Hsp47 $(47 \mathrm{kDa})$ and collagen IV (170-185 kDa) (Figure 2, lane 1). The 94$\mathrm{kDa}$ band also shown in Figure 2 (lane 1) is probably Grp94. Grp94 (glucose-related protein, $94 \mathrm{kDa}$ ) is an ER-resident protein known to form protein complexes with collagen and Hsp47 in previous studies $(14,16)$. AntiSec61 $\alpha$ antibodies immunoprecipitated Sec61 $\alpha$ and also Hsp47, collagen IV, and Grp94 (Figure 2, lane 2). Treatment of the samples with collagenase digested the high molecular weight bands (170 and $185 \mathrm{kDa}$ ), confirming that these, in fact, correspond to collagen chains (Figure 2, lanes 3 and 4). 
To confirm the presence of both TRAM and Sec61 $\alpha$ in F9 cell membrane-bound polysomes after treatment with retinoic acid, enhanced chemiluminescence Western blotting using specific antibodies against TRAM (28) and Sec61 $\alpha$ was employed (Figure 3). Sec61 $\alpha$ was detected in retinoic acid-treated (Figure 3, lane 4) but not in untreated cells (Figure 3, lane 3). Interestingly, the other component of the protein-conducting channel, TRAM, was seen in both control and retinoic acid-treated samples (Figure 3, lanes 1 and 2). TRAM was previously shown to mediate protein translocation in mammalian cells (28).

It was also important to determine whether Sec61 $\alpha$ production is influenced by heat shock. Hsp47 is constitutively expressed, and also has its production increased by stress including heat shock (29). After heat shock, Hsp47 protein levels rapidly increase through an activation of heat shock transcriptional factors (13). Western blots using anti-Sec61 $\alpha$ antibodies demonstrated Sec61 $\alpha$ in samples from both control and heat shocktreated cells following retinoic acid treatment (Figure 4, lanes 2 and 4). Sec61 $\alpha$ was not detected in untreated control cells (incubated at $37^{\circ} \mathrm{C}$; Figure 4 , lane 1) or in retinoic acid nontreated heat-shocked cells (incubated at $43^{\circ} \mathrm{C}$; Figure 4 , lane 3 ).

\section{Discussion}

Retinoic acid is an established regulator of epithelial cell differentiation in vivo and in vitro (30). One of the major physiological functions of retinoic acid is to prevent squamous differentiation (23,31). Squamous metaplasia, which develops during vitamin A deficiency, can be reversed by supplementation with retinoic acid (23). Furthermore, retinoic acid suppresses squamous cell differentiation that occurs spontaneously or induced by calcium ions in cultured normal keratinocytes or tracheal cells (23).

F9 cells comprise a cultured teratocarci- noma cell line which can be induced to differentiate into parietal endodermal cells (primitive endoderm-like cells) in the presence of retinoic acid and dibutyryl cAMP (32). The phenotype of the new cell type is characterized by synthesis of plasminogen activator, laminin and type IV collagen and by low levels of alkaline phosphatase and lactase dehydrogenase. The cell type generated by this induction is not dependent upon

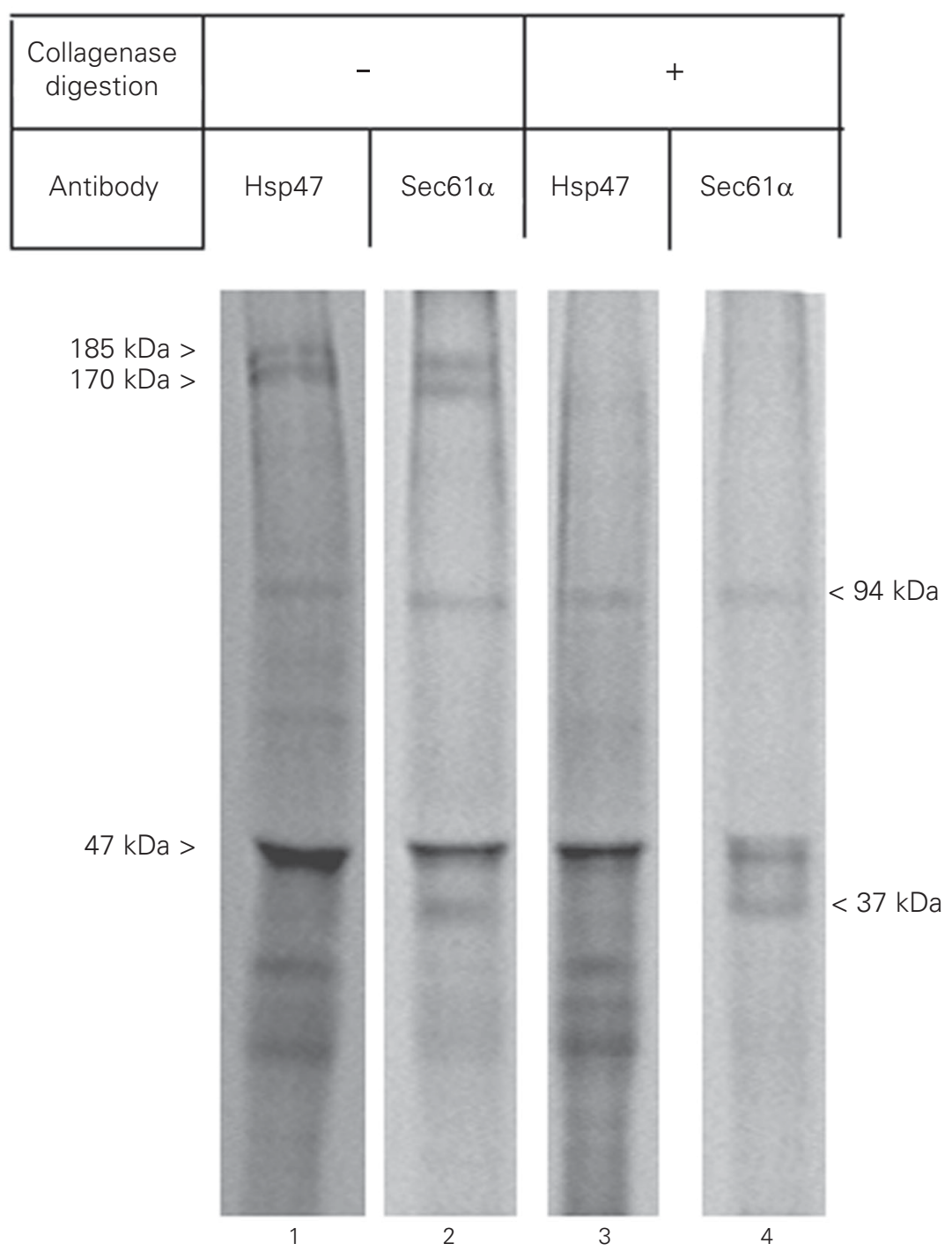

Figure 2. Immunoprecipitation with anti-Hsp47 and anti-Sec61 $\alpha$ antibodies and collagenase digestion of retinoic acid-treated membrane-bound collagen IV microsomes following treatment with DSP. Microsomes were immunoprecipitated with anti-Hsp47 (lanes 1 and 3) and anti-Sec61 $\alpha$ (lanes 2 and 4) antibodies. Collagenase digestion completely disrupted collagen microsomes (lanes 3 and 4). 


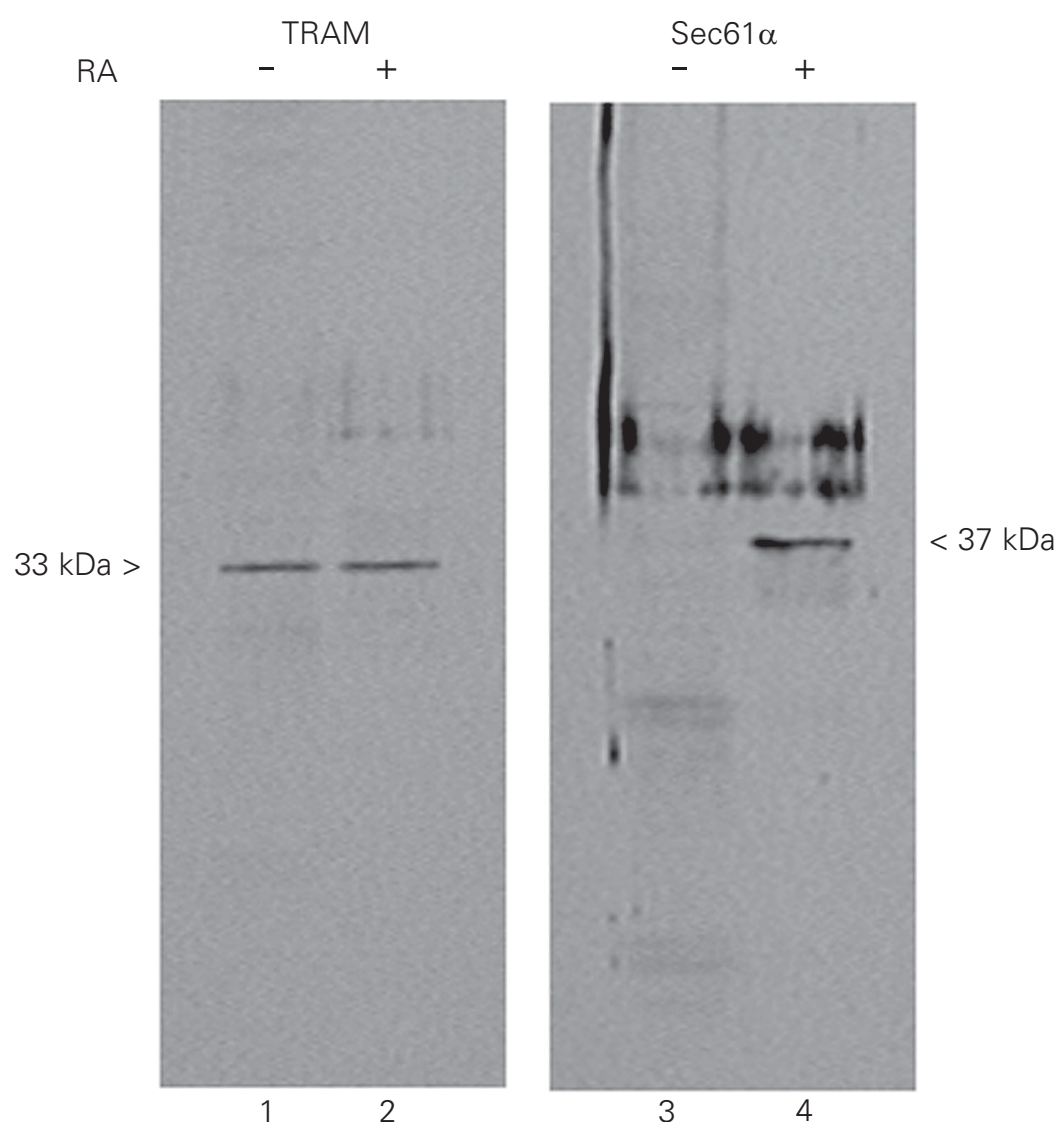

Figure 3 - Distribution of translocating chain-associating membrane protein (TRAM) and Sec61 $\alpha$ using the Western blotting technique with enhanced chemiluminescence following retinoic acid (RA) treatment. F9 cells were incubated at $37^{\circ} \mathrm{C}$ with (lanes 2 and 4) or without (lanes 1 and 3) retinoic acid for 4 days. Antibodies against TRAM (lanes 1 and 2) and Sec61 $\alpha$ (lanes 3 and 4) were applied and the nitrocellulose paper was then exposed to radiographic film. the continued presence of either compound, but the cAMP agents are active only on F9 cells that have been treated with retinoic acid $(33,34)$. This differentiation of the tumorigenic F9 stem cells results in the loss of their tumorigenicity (32). This differentiation response of F9 cells is irreversible, fairly synchronous, and rapid within 24 to $48 \mathrm{~h}$ (34).

It is unclear at the present time whether an intracellular binding protein mediates all of the actions of retinoic acid in cells. There has also been no convincing evidence in any system that retinoic acid regulates transcription of specific genes including Sec61 $\alpha$. Although the mechanism whereby retinoic acid regulates gene expression and differentiation is not completely understood, it is likely that high-affinity retinoic acid receptors and/ or binding proteins may be involved.

The delineation of translocation mechanisms in mammalian cells is still incomplete. However, several investigators have provided evidence that the ER membrane glycoproteins TRAM and the Sec61p complex are components of the mammalian ER translocon that participates in protein translocation (2). These translocon proteins may associate with ER proteins during the translocation of secretory proteins. Candidates for this asso-

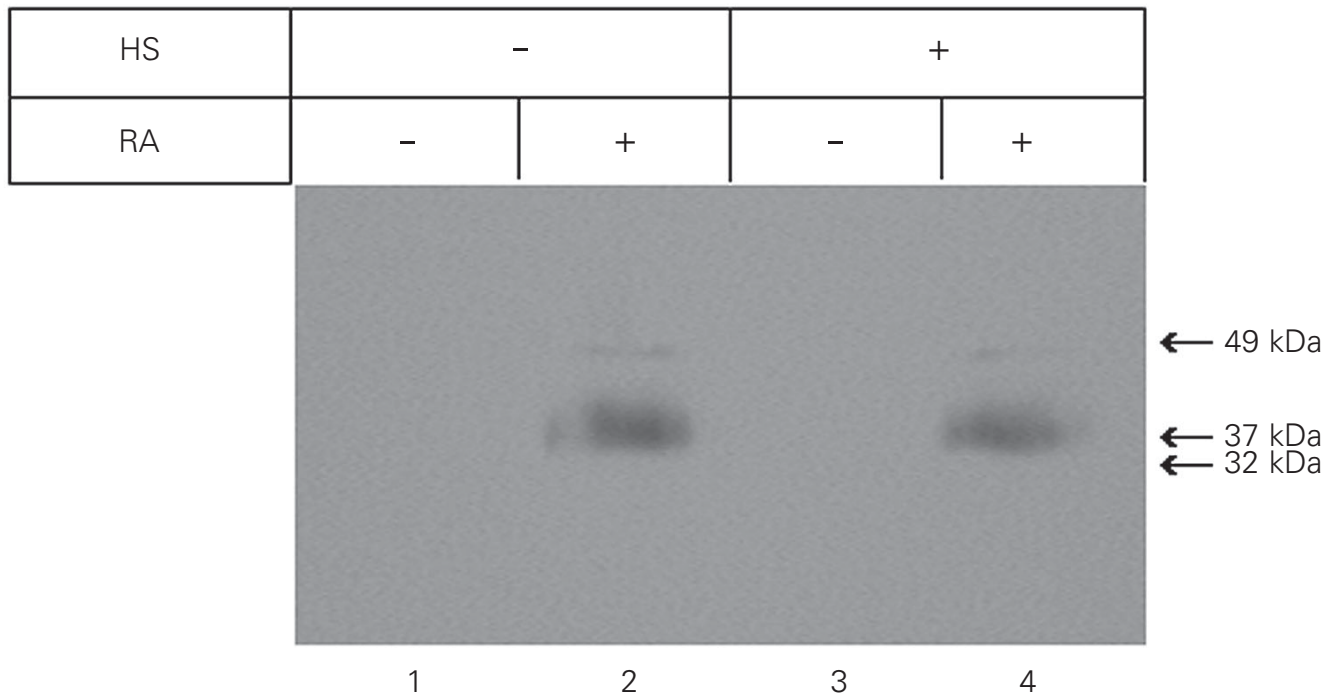

Figure 4. Distribution of Sec61 $\alpha$ using the Western blotting technique with enhanced chemiluminescence following retinoic acid (RA) and heat shock (HS) treatment. F9 cells were either incubated at $37^{\circ} \mathrm{C}$ (control cells, lanes 1 and 2) or at $43^{\circ} \mathrm{C}$ (heatshocked cells, lanes 3 and 4) for $90 \mathrm{~min}$. In some cases, F9 cells were treated with all-trans retinoic acid for 4 days (lanes 2 and 4). Antibodies against Sec61 $\alpha$ were added and the nitrocellulose paper was then exposed to radiographic film. 
ciation include components of the ribosomebinding site or the major component of the mammalian homolog of the Sec61p complex, $\operatorname{Sec} 61 \alpha$ (2). The precise localization of Sec61 $\alpha$ in the ER membrane has not been determined, although it is likely that portions of Sec $61 \alpha$ project into the ER lumen. Sec61 $\alpha$ was localized adjacent to nascent polypeptides that are being translocated through the ER membrane (8). Since Sec61 $\alpha$ proteins were not associated with long translating polypeptide chains, it has been suggested that $\operatorname{Sec} 61 \alpha$ proteins reside near nascent chains at the beginning of their membrane passage (2). Furthermore, Sec61 $\alpha$ was essential for the translocation of certain nascent polypeptide chains through the ER membrane (2).

It is not clear whether Sec61 $\alpha$ binding to translocating proteins occurs through the enhanced production and utilization of $\operatorname{Sec} 61 \alpha$, or whether it is dependent on the stage of cell differentiation. It is also not known to date whether Sec61 $\alpha$ is constitutively expressed and produced in collagen-producing cells. Accordingly, in the present study we investigated the production of $\operatorname{Sec} 61 \alpha$ and other translocon components following retinoic acid treatment. The production of Sec $61 \alpha$ markedly increased after retinoic acid treatment. Sec61 $\alpha$ production was not detected in untreated F9 cells. However, another translocon component, TRAM, was present in both retinoic acid-treated and control samples.

The relevance of the undetectable levels of Sec61 $\alpha$ in undifferentiated F9 cells is not known. Sec61 $\alpha$ was essential for the translocation of secretory proteins (2). The mechanism whereby these tumor cells secrete proteins without detectable amounts of Sec61 $\alpha$ is still not well understood. Further experiments are needed to clarify the role of $\operatorname{Sec} 61 \alpha$ in collagen-producing cells. Among mammalian species, the cDNA sequence for the Sec61 $\alpha$ gene is known for rats, dogs, and humans, but the cDNA sequence for the mouse Sec61 $\alpha$ gene has not been reported.

A number of explanations currently exist for the source of the forces that drive the newly synthesized chains into the lumen of the ER. Topogenic sequences located in translocon components may influence translocation into the ER $(35,36)$. However, another possibility is that simple elongation of the nascent chain drives extrusion of the polypeptide into the ER and the protein translocation channel is a passive pore (37). Consequently, this channel is without directional preference for polypeptide movement. Thus, the bias in random movement of a polypeptide resulting in vectorial translocation is driven by nascent chain elongation and is sustained by inclusion of a stop codon or by post-translational events, such as glycosylation, folding and/or binding to chaperones (38). While it is not known whether distinctive chaperones or translocons are utilized for specialized proteins such as procollagen, there is strong evidence to suggest that some classes of proteins use distinctive machinery for their organization. For example, although evidence strongly indicated the participation of TRAM in the translocation of $\beta$-lactamase and prepro- $\alpha$-factor, elimination of this translocon component only reduced the translocation efficiency for preprolactin (3).

Using a cross-linking reagent on membrane-bound polysome extracts from retinoic acid-induced F9 teratocarcinoma cells, Sec61 $\alpha$ is shown in this study to co-precipitate with collagen IV, Hsp47, and Grp94. These results indicate that a major component of the translocon complex, Sec61 $\alpha$, may associate early with nascent collagen IV polypeptides and ER-resident molecular chaperones during translation/translocation. These data suggest that $\operatorname{Sec} 61 \alpha$ may form complexes with Hsp47 and other ER proteins during the constitutive synthesis of collagen IV by F9 cells after retinoic acid treatment.

Hsp47, a collagen-bound heat shock protein, has been found associated with evolv- 
ing chains of procollagen associated with polysomes by binding to the Gly-X-Y regions of nascent collagen chains (39). Sauk et al. (15) have demonstrated that Hsp47 associates with Grp78, Grp94 and nascent procollagen I to form large complexes. Gorlich et al. (40) have shown the association of TRAM and Sec61 $\alpha$ with complexes of proteins after photocrosslinking. High et al. (3) demonstrated the formation of protein complexes with Sec $61 \alpha$ after chemical crosslinking with DSP. These data support the hypothesis of a successive action of molecular chaperones.

The production of $\operatorname{Sec} 61 \alpha$ was shown to be markedly increased following retinoic acid treatment. Another translocon component, TRAM, was demonstrated to be present in both retinoic acid-treated and control samples. Therefore, the absence or limited production of Sec61 $\alpha$ in F9 cells prior to retinoic acid treatment is not restricted to other members of the translocation machinery. The relevance of the diminished or absent production of Sec61 $\alpha$ in undifferentiated F9 cells is not known. Also, the mechanism whereby these tumor cells secrete proteins without detectable amounts of Sec61 $\alpha$ is still not well understood.

\section{References}

1. Simon SM \& Blobel G (1991). A protein conducting channel in the endoplasmic reticulum. Cell, 65: 371-380.

2. Kellaris KV, Bowen S \& Gilmore R (1991). ER translocation intermediates are adjacent to a non-glycosylated 34-KD integral membrane protein. Journal of Cell Biology, 114: 21-33.

3. High S, Gorlich D, Wiedmann M, Rapoport TA \& Dobberstein B (1991). The identification of proteins and signal anchor sequences during their targeting to and insertion into the membrane of the ER. Journal of Cell Biology, 113: 35-44.

4. Knight BC \& High S (1998). Membrane integration of Sec61-alpha: a core component of the endoplasmic reticulum translocation complex. Biochemical Journal, 331: 161-167.

5. Greenfield JJ \& High S (1999). The sec61 complex is located in both the ER and ER-Golgi intermediate compartment. Journal of Cell Science, 112: 1477-1486.

6. Stirling CJ, Rothblatt J, Hosobuchi M, Deshaies R \& Schekman R (1992). Protein translocation mutants defective in the insertion of integral membrane proteins into the endoplasmic reticulum. Molecular Biology of the Cell, 3: 129-142.

7. Plemper RK, Bordallo J, Deak PM, Taxis C, Hitt R \& Wolf DH (1999). Genetic interaction of $h r d 3 p$ and Der3p/Hrd1p with sec61p suggest a retro-translocation complex mediating protein transport for ER degradation. Journal of Cell Science, 112: 4123-4134.

8. Mothes W, Prehn S \& Rapoport TA (1994). Systematic probing of the environment of a translocating secretory protein during translocation through the ER membrane. EMBO Journal, 13: 3973-3982.

9. Shroff B, Smith T, Norris K, Pileggir R \& Sauk JJ (1993). HSP47 is localized to regions of type I collagen production in developing murine femurs and molars. Connective Tissue Research, 29: 273286.

10. Nakai A, Hirayoshi S, Saga S, Yamada KM \& Nagata K (1989). The transfomation-sensitive heat shock protein $\mathrm{Hsp} 47$ binds specifically to fetuin. Biochemical and Biophysical Research Communications, 164: 259-264.

11. Nagata K, Saga S \& Yamada KM (1986). A major collagen binding protein of chick embryo fibroblasts is a novel heat shock protein. Journal of Cell Biology, 103: 223-229.
12. Nagata K \& Yamada KM (1986). Phosphorylation and transformation sensitivity of a major collagen-protein of fibroblasts. Journal of Biological Chemistry, 261: 7531-7536.

13. Bielinska M \& Wilson DB (1995). Regulation of J6 gene expression by transcription factor GATA-4. Biochemical Journal, 307: 183-189.

14. Ferreira LR, Norris K, Smith T, Hebert C \& Sauk JJ (1994). Association of Hsp47, Grp78, Grp94 with procollagen supports the successive or coupled action of molecular chaperones. Journal of Cellular Biochemistry, 56: 518-526.

15. Sauk JJ, Smith T, Norris K \& Ferreira LR (1994). Hsp47 and the translation-translocation machinery cooperate in the production of alpha1 (I) chains of type I procollagen. Journal of Biological Chemistry, 269: 3941-3946.

16. Ferreira LR, Norris K, Smith T, Hebert C \& Sauk JJ (1996). Hsp47 and other ER-resident molecular chaperones form heterocomplexes with each other and with collagen type IV chains. Connective Tissue Research, 33: 265-273.

17. Moriyana T, Kawada N, Ando A, Yamauchi A, Horio M, Nagata K, Imai E \& Hori M (1998). Up-regulation of Hsp47 in the mouse kidneys with unilateral ureteral obstruction. Kidney International, 54: 110-119.

18. Razzaque MS, Hossain MA, Kohno S \& Taguchi T (1998). Bleomycininduced pulmonary fibrosis in rat is associated with increased expression of collagen-binding heat shock protein (Hsp) 47. Virchows Archiv, 432: 455-460.

19. Cheng M, Razzaque MS, Nazneen A \& Taguchi $T$ (1998). Expression of the heat shock protein 47 in gentamicin-treated rat kidneys. Journal of Experimental Pathology, 79: 125-132.

20. Razzaque MS, Shimnokawa I, Nazneen A, Higami $Y$ \& Taguchi $T$ (1998). Age-related nephropathy in the Fisher 344 rat associated with over expression of collagens and collagen-binding heat shock protein 47. Cell and Tissue Research, 293: 471-478.

21. Coletta RD, Almeida O, Graner E, Page R \& Bozzo L (1998). Differential proliferation of fibroblasts cultured from hereditary gingival fibromatosis and normal gingiva. Journal of Periodontal Research, 33: 469-475.

22. Wang SY \& Gudas LJ (1990). A retinoic acid inducible mRNA from 
F9 teratocarcinoma cells encodes a novel protease inhibitor homologue. Journal of Biological Chemistry, 265: 15818-15822.

23. Jetten AM, Nervi C \& Volberg TM (1992). Control of squamous differentiation in tracheobronchial and epidermal epithelial cells: Role of retinoids. Journal of the National Cancer Institute. Monographs, 13: 93-100.

24. Laemmli UK (1970). Cleavage of structural proteins during the assembly of the head of bacteriophage T4. Nature, 227: 680-685.

25. Bonner WM \& Laskey RA (1974). A film detection method for tritium-labeled proteins and nucleic acids in polyacrylamide gels. European Journal of Biochemistry, 46: 83-88.

26. Vedeler A, Pryme IF \& Hesketh JE (1991). The characterization of free cytoskeletal and membrane-bound polysomes in Krebs II ascites and 3T3 cells. Molecular and Cellular Biochemistry, 100: 183-193.

27. Towbin H, Staehelin T \& Gorgon J (1979). Electrophoretic transfer of proteins from polyacrylamide gels to nitrocellulose sheets: procedure and some applications. Proceedings of the National Academy of Sciences, USA, 76: 4350-4354.

28. Gorlich D \& Rapoport TA (1993). Protein translocation in proteoliposomes reconstructed from purified components of the endoplasmic reticulum membrane. Cell, 75: 615-630.

29. Coletta RD, Almeida OP, Ferreira LR, Reynolds MA \& Sauk JJ (1999). Increase in expression of Hsp47 and collagen in hereditary gingival fibromatosis is modulated by stress and terminal procollagen n-propeptides. Connective Tissue Research, 40: 237-249.

30. Zou CP, Clifford JL, Xu XC, Sacks PG, Chambon P, Hong WK \& Lotan $R$ (1994). Modulation by retinoic acid (RA) of squamous cell differentiation, cellular RA binding proteins, and nuclear RA receptors in human head and neck squamous cell carcinoma cell lines. Cancer
Research, 54: 5479-5487.

31. Fischer HS, Berti I, Schatz DS, Humpel C \& Saria A (2000). Retinoic acid treatment enhances the acetylcholine contents in the human teratocarcinoma cell line NTera-2. Regulatory Peptides, 96: 59-63.

32. Strickland S, Smith KK \& Marotti KR (1980). Hormonal induction of differentiation in teratocarcinoma cells: Generation of parietal endoderm by retinoic acid and dibutyryl cAMP. Cell, 21: 347-355.

33. Strickland S \& Mahdavi V (1978). The induction of differentiation in teratocarcinoma stem cells by retinoic acid. Cell, 15: 393-403.

34. Jetten A, Jetten M \& Sherman M (1979). Stimulation of differentiation of several murine embryonal carcinoma cell lines by retinoic acid. Experimental Cell Research, 124: 381-391.

35. Lingappa VR (1991). More than just a channel: provocative new features of protein traffic across the ER membrane. Cell, 65: 527-530.

36. Walter P (1992). Protein translocation - Traveling by TRAM. Nature, 357: 22-23.

37. Perara E, Rothman RE \& Lingappa VR (1986). Uncoupling translocation from translation: Implications for transport of proteins across membranes. Science, 232: 348-352.

38. Ooi CE \& Weiss J (1992). Bidirectional movement of a nascent polypeptide across microsomal membranes reveals the requirement for vectorial translocation of proteins. Cell, 71: 87-96.

39. Sauk JJ, Norris K, Hebert C, Ordonez J \& Reynolds M (1998). Hsp47 binds to the KDEL receptor and cell surface expression is modulated by cytoplasmic and endosomal $\mathrm{pH}$. Connective Tissue Research, 37: 105-119.

40. Gorlich D, Hartman E, Prehn S \& Rapoport TA (1992). A protein of the endoplasmic reticulum is involved early in polypeptide translocation. Nature, 357: 47-52. 